\title{
Aplasia Cutis Congenita with Unusual Localization - Case Report
}

\author{
Anca Chiriac ${ }^{1,2,3}$, Adrian Naznean ${ }^{4}$, Cristian Podoleanu ${ }^{5}$, Simona Stolnicu ${ }^{6,7}$ \\ 1 Nicolina Medical Centre, Department of Dermatology, lași, Romania \\ 2 Apollonia University, Iași, Romania \\ 3 "P. Poni” Research Institute, Romanian Academy, Iași, Romania \\ 4 Department of Foreign Languages, University of Medicine, Pharmacy, Science and Technology, Târgu Mureș, Romania \\ 5 Department of Internal Medicine, University of Medicine, Pharmacy, Science and Technology, Târgu Mureș, Romania \\ ${ }^{6}$ Department of Pathology, University of Medicine, Pharmacy, Science and Technology, Târgu Mureș, Romania \\ 7 Histopat Invest Laboratory, Târgu Mureș, Romania
}

\section{CORRESPONDENCE}

\section{Cristian Podoleanu}

Str. Gheorghe Marinescu nr. 38

540139 Târgu Mureș, Romania

Tel: +40 265215551

E-mail: podoleanu@me.com

\section{ARTICLE HISTORY}

Received: October 12, 2019

Accepted: December 10, 2019
Anca Chiriac • Str. Hatman Sendrea nr. 2, 700613 lași, Romania. Tel: +40332808703

Adrian Naznean • Str. Gheorghe Marinescu nr. 38 540139 Târgu Mureș, Romania. Tel: +40 265215551

Simona Stolnicu • Str. Gheorghe Marinescu nr. 38 , 540139 Târgu Mures, Romania. Tel: +40 265215551

\section{ABSTRACT}

Congenital skin aplasia, known more as aplasia cutis congenita (ACC), is a rare congenital disease, characterized by absence of the skin, observed since birth, more often affecting the scalp and rarely the trunk or limbs. We report here for the first time a non-syndromic localized ACC, characterized by a small solitary area of skin atrophy on the cervical area in a healthy 3-day-old female infant.

Keywords: aplasia cutis, skin atrophy, congenital skin disorders

\section{INTRODUCTION}

Congenital skin aplasia, known more as aplasia cutis congenita (ACC), is a rare congenital disease, characterized by absence of the skin, observed since birth, more often affecting the scalp and rarely the trunk, abdomen, face, or limbs. The skin defect can be localized or extensive, syndromic or non-syndromic. Its morbidity, mortality, and treatment are correlated with the anatomical site and size, and its associated complications include skin lesions as well as other malformations or pathologic conditions.

We report a non-syndromic, localized ACC, characterized by a small area of skin atrophy on the cervical area.

\section{CASE REPORT}

A 3-day-old female infant was transferred for consultation to the Clinic of Dermatology with a diagnosis of a congenital skin defect on the anterior cervical area (neck). She was born from a normal pregnancy, with no complications dur- 


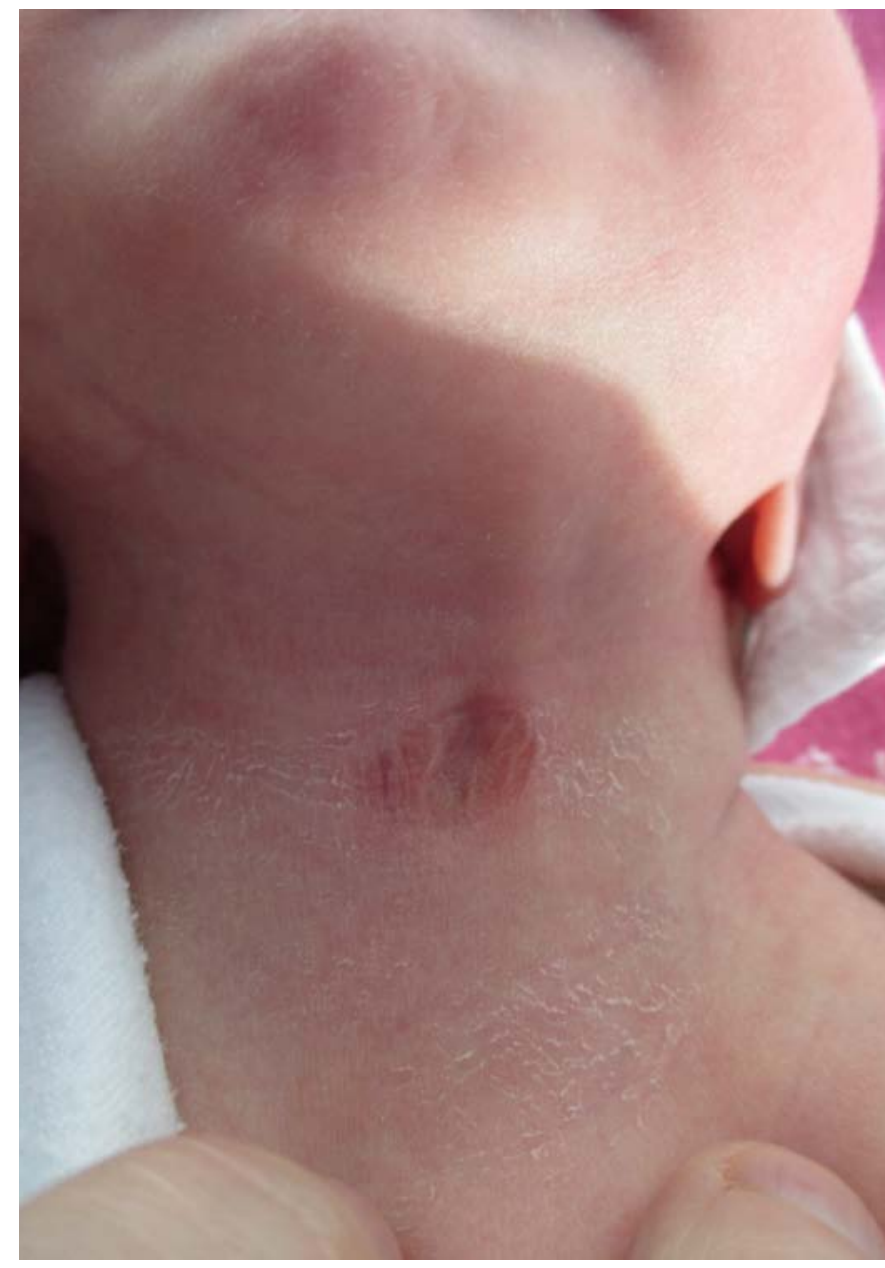

FIGURE 1. Clinical examination revealed a small area of $1.2 / 0.8 \mathrm{~cm}$ of atrophic skin limited to the anterior area of the neck

ing delivery. The infant was born at term, healthy, from healthy parents without consanguinity. The mother had not been diagnosed with infections during pregnancy; also, no drug intake and no traumatic events have been recorded during pregnancy or at birth.

First clinical diagnosis was post-traumatic wound, because it looked like an excoriation. Suspicion of ACC or epidermolysis bullosa led to genetic and dermatological examinations. The genetic evaluation and dermatological clinical examination concluded non-syndromic, localized ACC limited to the anterior cervical area (Figure 1). A small area of $1.2 / 0.8 \mathrm{~cm}$ of atrophic skin was observed on the neck with no other associated skin anomalies. Palpation confirmed focal absence of the skin, with discrete wrinkling, with no involvement of underlying structures. Close follow-up was recommended, but no treatment. General clinical evaluation as well as additional radiologic examinations did not reveal other pathologic conditions or malformations of the newborn.

\section{DISCUSSIONS}

ACC is a rare congenital skin disorder, with an overall incidence of 1:3,000-10,000 births. ${ }^{1}$ ACC is considered nowadays a heterogeneous group of skin disorders, with different associations of certain malformation syndromes, the so-called syndromic ACC. ${ }^{2}$ The hallmark of the disease is the complete absence of the skin, mostly on the scalp and extremities. Recently, it has been postulated that ACC can be diagnosed in 1 of 3,000 newborns. ${ }^{2,3}$

ACC of the scalp is well documented, and it is statistically proved that it can involve the scalp bones in $20-30 \%$ of cases with significant complications such as hemorrhage, thrombosis, and infections affecting the central nervous system. ${ }^{4,5}$ Currently, suggestions for evaluating ACC of the scalp with ultrasound or MRI are based on clinical clues: large area of skin defects (size more than $5 \mathrm{~cm}$ ), midline vertex position, vascular stains or nodular appearance, and the presence of hair collar sign. ${ }^{6}$ Defects of the skull should be suspected in large lesions, mainly greater than $10 \mathrm{~cm}$, even in the absence of ulceration. ${ }^{7}$

ACC on the neck is extremely rare; a severe form of ACC has been reported in a newborn who associated junctional epidermolysis bullosa and congenital gastrointestinal atresia. A large ACC was located circularly around the neck with a restrictive appearance and also on the left forearm, hand and knee, right foot and lower leg. ${ }^{8}$ In contrast, ACC as a solitary atrophic small lesion located on the neck in a healthy female newborn has not been previously reported, to the best of our knowledge. In this case, no other malformations were revealed, and therefore, close followup of the lesion was recommended only.

\section{CONCLUSION}

Aplasia cutis congenita is a rare disease, generally observed within the first days after birth. It may be accompanied by other malformations, and it can lead to several complications that can range from small hemorrhages to thrombosis of the underlying venous system, infection, and meningitis if located in the cephalic extremity. Given the possible complications than can be associated with increased morbidity and mortality, the diagnosis of congenital absence of the skin should be taken into consideration in case of skin lesions occurring in newborns, especially located in the scalp and neck area.

\section{CONFLICT OF INTEREST}

Nothing to declare. 


\section{REFERENCES}

1. Rogvi Rá, Sommerlund M, Vestergaard ET. Aplasia cutis congenita. Ugeskr Laeger. 2015;12;177:V09140483.

2. Frieden IJ. Aplasia cutis congenita: a clinical review and proposal for classification. J Am Acad Dermatol. 1986;14:646-660.

3. Marneros AG. Genetics of aplasia cutis reveal novel regulators of skin morphogenesis. J Invest Dermatol. 2015;135:666-672.

4. Demmel U. Clinical aspects of congenital skin defects. I. Congenital skin defects on the head of the newborn. Eur J Pediatr. 1975;121:21-50.

5. Frieden IJ. Aplasia cutis congenita: a clinical review and proposal for classification. J Am Acad Dermatol. 1986;14:646-660.

6. Patel DP, Castelo-Soccio L, Yan AC. Aplasia cutis congenita: Evaluation of signs suggesting extracutaneous involvement. Pediatric Dermatology. 2018;35:E59-E61.

7. Kim JY, Lee YK, Ko SY, et al. Clinical course of aplasia cutis congenita. J Korean Soc Neonatol. 2011;18:359-364.

8. Trah J, Has C, Hausser I, et al. Integra ${ }^{\circledR}$-dermal regeneration template and split-thickness skin grafting: a therapy approach to correct aplasia cutis congenita and epidermolysis bullosa in Carmi syndrome. Dermatol Ther (Heidelb). 2018;8:313 